\title{
Antibiotic resistance, virulence-associated genes analysis and molecular typing of Klebsiella pneumoniae strains recovered from clinical samples
}

\author{
Amir Mirzaie and Reza Ranjbar
}

\begin{abstract}
Klebsiella pneumoniae is a multidrug-resistant (MDR) opportunistic pathogen that causes nosocomial infections. Virulence analysis and molecular typing as powerful approaches can provide relevant information on K. pneumoniae infection. In the current study, antibiotic resistance, virulence-associated genes analysis, as well as molecular typing of K. pneumoniae strains were investigated. Out of 505 clinical samples collected from hospitalized patients, 100 K. pneumoniae strains were isolated by standard microbiological methods and subjected to the phenotypic and genotyping analysis. The highest prevalence of resistance was observed against ciprofloxacin (75\%), trimethoprim-sulfamethoxazole (73\%) and nitrofurantoin (68\%). Virulence associated genes including entB, traT, ybts, magA, iucC, htrA and rmpA were found in $80 \%, 62 \%, 75 \%, 5 \%, 30 \%, 72 \%$ and $48 \%$, of the isolates, respectively. The prevalence of biofilmassociated genes including $m r k A$, fimH, and $m r k D$ were equally $88 \%$ for all tested isolates. Moreover, the efflux pump genes including AcrAB, To/C and mdtK were observed in 41 (41\%), 33 (33\%) and 26 (26\%) of the strains respectively. A significant statistical association was observed between MDR strains and high expression of efflux pump and biofilm genes. The K. pneumoniae strains were differentiated into 11 different genetic patterns using the repetitive element sequence-based PCR (rep-PCR) technique. High prevalence of resistance, presence of various virulence factors, high level of efflux pump, and biofilm gene expression in diverse clones of $K$. pneumoniae strains pose an important health issue in clinical settings.
\end{abstract}

Keywords: Klebsiella pneumoniae, Antibiotic resistance, Virulence associated genes, Efflux pumps, Biofilm, Gene expression, Rep-PCR

\section{Introduction}

Klebsiella pneumoniae is a non-motile Gram-negative bacterium that belongs to the Enterobacteriaceae family (José et al. 2019). K. pneumoniae is considered as one of the opportunistic nosocomial pathogens, especially in Iran (Ranjbar et al. 2019). This organism causes a variety of diseases such as bacteremia, pneumonia and urinary tract infection. In recent years, K. pneumoniae has

*Correspondence: ranjbarre@gmail.com

Molecular Biology Research Center, Systems Biology and Poisonings

Institute, Baqiyatallah University of Medical Sciences, Tehran, Iran attracted the attention of researchers around the world due to its disease severity, resistance against many antibiotics and the difficulty of the treatment (Ranjbar et al. 2016a, b, 2019). Increased multidrug-resistant (MDR) $K$. pneumoniae strains in recent years may be due to overuse and uncontrolled use of antimicrobial agents to treat diseases and infections caused by this bacterium (Fuzi et al. 2020). K. pneumoniae has developed several mechanisms for resistance to different antimicrobials (Wanjiang et al. 2019). One of the important mechanisms for developing the MDR is efflux pump systems and biofilm formation capacity (Yoon et al. 2020). Efflux pumps are 
protein-based structures that are capable to extrude the different toxic substances out of cells (Montazeri et al. 2020). The AcrAB efflux pump system which belongs to the Resistance Nodulation Division (RND) plays an important role in the development of $K$. pneumoniae MDR strains (Xu et al. 2019; Naha et al. 2020; Yoon et al. 2020; Grimsey et al. 2020). The AcrAB-TolC efflux pump is composed of a periplasmic component (AcrA), a transporter located in the inner membrane (AcrB) and an outer membrane compartment (TolC). The AcrAB-TolC efflux pump has a critical role in resistance to multiple antibiotics such as quinolones, tetracycline, and chloramphenicol in MDR strains of K. pneumoniae (Shao et al. 2020).

The biofilm-forming ability in $K$. pneumoniae allows the protection of strains from the host immune response and antibiotics in MDR isolates (Sundaramoorthy et al. 2021) and different biofilm-related genes including mrk (type 3 fimbriae), fimH-1 (type 1 fimbrial adhesion) are involved in the biofilm formation (Sahoo et al. 2019; Ranjbar et al. 2019). It was shown that the efflux pumps play an important role in antibiotic resistance and biofilm formation (Tang et al. 2020). Several studies showed a significant correlation between the $K$. pneumoniae antibiotic resistance with efflux pump and biofilm formation ability (Vuotto et al. 2017). Subramanian et al. (2012) found $80 \%$ of biofilm-forming isolates from 100 clinical samples showed an MDR phenotype (Subramanian et al. 2012). Several virulence-associated genes include those encoding regulators of mucoid phenotype A $(r m p A)$, enterobactin biosynthesis gene $($ ent $B)$, outer membrane protein-coding gene (traT), yersiniabactin biosynthesis gene (ybts), mucoviscosity-associated gene A (magA), iron siderophores aerobactin synthase gene $(i u c C)$ and periplasmic serine endoprotease DegP-like $(h t r A)$ have a crucial role in the pathogenicity of $K$. pneumoniae strains (Highsmith et al. 1985). Molecular typing of K. pneumoniae can be useful in terms of prevention of nosocomial infections in hospitals. (Pasala et al. 2020). Moreover, determination of dominant genotype among isolates can be important for understanding the source of infection and applying prevention procedures (Mukherjee et al. 2019). Various methods including pulsed field gel electrophoresis (PFGE), enterobacterial repetitive intergenic consensus-polymerase chain reaction (ERIC-PCR), randomly amplified polymorphic DNA (RAPD), and repetitive extragenic palindromic polymerase chain reaction (rep-PCR) have been used for molecular typing of $K$. pneumoniae strains. The rep-PCR has been has been successfully used for genotyping of K. pneumoniae from various sources. The advantages of rep-PCR over other molecular typing methods include the ability to differentiate between closely related strains of bacteria as well as being a simple, quick, inexpensive, and reliable highthroughput genotyping method (Alharthi et al. 2016).

Due to high prevalence of MDR isolates of K. pneumonia in Iran (Heidary et al. 2018; Jafari et al. 2019), the aim of this study was to evaluate the antibiotic resistance profile, distribution of virulence genes, efflux pump and biofilm gene expression, as well as, molecular typing of clinically recovered $K$. pneumoniae strains using rep-PCR.

\section{Methods \\ Bacterial isolates and identification}

In this study, a total of 505 clinical samples including blood, urine and cerebrospinal fluid (CSF) were collected from patients admitted to two major hospitals in Tehran, capital of Iran, from January 2018 to July 2019. The $K$. pneumoniae strains were identified using conventional microbiological tests (Collee 2007). The isolated strains were stored at $-20{ }^{\circ} \mathrm{C}$ in brain heart infusion broth containing $20 \%$ glycerol for further investigation.

\section{Antimicrobial susceptibility test}

The antibiotic susceptibility of $K$. pneumoniae strains was performed based on the Kirby-Bauer disk diffusion method according to the Clinical and Laboratory Standards Institute (CLSI) guidelines (Wayne 2018). The antimicrobial susceptibility assays to 17 antibiotics were performed using commercially available antibiotics including ceftazidime $(30 \mu \mathrm{g})$, cefotaxime $(30 \mu \mathrm{g})$, cefoxitin $(30 \mu \mathrm{g})$, ceftriaxone $(30 \mu \mathrm{g})$, tobramycin $(10 \mu \mathrm{g})$, gentamicin $(10 \mu \mathrm{g})$, streptomycin $(30 \mu \mathrm{g})$, nalidixic acid $(30 \mu \mathrm{g})$, ciprofloxacin $(5 \mu \mathrm{g})$, Imipenem $(10 \mu \mathrm{g})$, cotrimoxazole $(1.25 / 23.75 \mu \mathrm{g})$, chloramphenicol $(30 \mu \mathrm{g})$, Amoxicillin/Clavulanic acid (AMC, 20/10 $\mu \mathrm{g}$ ), meropenem $(10 \mu \mathrm{g})$, clindamycin $(30 \mu \mathrm{g})$, polymixin B $(10 \mu \mathrm{g})$, tetracycline $(30 \mu \mathrm{g})$ (MAST, Group Ltd., Merseyside, UK). The plates were incubated at $37^{\circ} \mathrm{C}$ for $24 \mathrm{~h}$ and subsequently, the inhibition zone diameters were recorded in millimeter and interpretation was carried out based on CLSI. K. pneumoniae ATCC 13,883 was used as a control in this study. Moreover, multidrug-resistant (MDR) isolates were detected based on their resistance to at least one agent in three or more antimicrobial classes.

\section{Efflux pump detection}

The phenotypic and qualitative detection of the efflux pump in K. pneumoniae strains was performed by Cartwheel method (Martins et al. 2011a, b). Briefly, the plates of Muller Hinton Agar culture media containing ethidium bromide were prepared and the culture medium was divided into 8 parts. Then the bacteria with $0.5 \mathrm{McFar}-$ land turbidity concentration were streaked on the plates. After $24 \mathrm{~h}$ of incubation at $37^{\circ} \mathrm{C}$, the plates were studied 
under UV transillumination. The strains that had efflux pumps did not show emission of fluorescence (Behdad et al. 2020).

\section{Biofilm formation test}

Phenotypic detection of biofilm formation was performed using Congo red agar test. Briefly, The K. pneumoniae strains were cultured in Brain Heart Infusion agar medium enriched with $5 \%(\mathrm{w} / \mathrm{v})$ sucrose and Congo red based on Freeman et al. (1989). The K. pneumoniae strains which formed biofilm exhibited dry dark crystalline colonies and considered exopolysaccharides producers (Hasan et al. 2020).

\section{Biofilm formation test using quantitative assay}

A quantitative biofilm formation test was performed in 96 well tissue culture plates. Briefly, $100 \mu \mathrm{l}$ of overnight culture with an optical density OD $600=0.1$ was added into wells. After $24 \mathrm{~h}$ incubation, each well was washed twice with PBS and then, stained with crystal violet for $15 \mathrm{~min}$. Finally, the stained cells were dissolved in 33\% $(\mathrm{v} / \mathrm{v})$ glacial acetic acid and the absorbance was read at $570 \mathrm{~nm}$. The strains were classified upon Donelli et al. 2012 as non-biofilm producers, weak biofilm producers, moderate biofilm former and strong biofilm producers. In addition, the standard strain $K$. pneumoniae ATCC 13,833 and LB broth were considered as a positive and negative control, respectively (Alkhudhairy et al. 2019).

\section{PCR detection of virulence associated genes}

The genomic DNA of each isolate was extracted by DNA extraction kit (Bioneer, Korea) based on to manufacturer's protocol. The frequency of ent $B$, trat and $r m p A$ virulence genes, $m d t k$, tolC and $a c r A B$ efflux pump, fimH-1, mrkA and $m r k B$ biofilm-associated genes were detected by PCR. The PCR conditions were as follow: Initial denaturing at $94{ }^{\circ} \mathrm{C}$ for $5 \mathrm{~min}$ followed by 30 cycles, each cycle contained $1 \mathrm{~min}$ at $94{ }^{\circ} \mathrm{C}$ for denaturation, $30 \mathrm{~s}$ for annealing (Table 1) and $60 \mathrm{~S}$ for extension steps and finally one cycle for the final extension at $72{ }^{\circ} \mathrm{C}$ for $10 \mathrm{~min}$. The primer of target genes is given in Table 1.

\section{Gene expression analysis of $a c r A B$ and $m r k A$ gene}

Gene expression analysis of AcrAB efflux pump and $m r k A$ biofilm was performed using quantitative RealTime PCR method in K. pneumoniae strains. Briefly, $100 \mu \mathrm{l}$ of each bacterial suspension were added into the 96 well plates and incubated for $18 \mathrm{~h}$ at $37^{\circ} \mathrm{C}$ aerobically.

Table 1 The primer sequences of target genes which used in this study

\begin{tabular}{|c|c|c|c|}
\hline Target gene & Primer sequence $\left(5^{\prime}\right.$ to 3$)$ & Annealing temperature $\left({ }^{\circ} \mathrm{C}\right)$ & References \\
\hline$a c r A B$ & $\begin{array}{l}\text { F ATCAGCGGCCGGATTGGTAAA } \\
\text { R CGGGTTCGGGAAAATAGCGCG }\end{array}$ & 53 & Wasfi et al. (2016) \\
\hline tolc & $\begin{array}{l}\text { F ATCAGCAACCCCGATCTGCGT } \\
\text { R CCGGTGACTTGACGCAGTCCT }\end{array}$ & 51 & \\
\hline$m d t k$ & $\begin{array}{l}\text { F GCGCTTAACTTCAGCTCA } \\
\text { R GATGATAAATCCACACCAGAA }\end{array}$ & 43 & \\
\hline iucC & $\begin{array}{l}\text { F TGGATTGATGCTCAAACTCTG } \\
\text { RTGCATCGCTCATTGACAGTA }\end{array}$ & & Wasfi et al. (2016) \\
\hline$m r k A$ & $\begin{array}{l}\text { F ACGTCTCTAACTGCCAGGC } \\
\text { R TAGCCCTGTTGTTTGCTGGT }\end{array}$ & 55 & Vuotto et al. (2017) \\
\hline$m r k D$ & $\begin{array}{l}\text { F CCACCAACTATTCCCTCGAA } \\
\text { R ATGGAACCCACATCGACATT }\end{array}$ & 43 & $\begin{array}{l}\text { Sahly et al. (2008), El Fertas- } \\
\text { Aissani et al. (2013) }\end{array}$ \\
\hline $\mathrm{fimH}$ & $\begin{array}{l}\text { F GCCAACGTCTACGTTAACCTG } \\
\text { R ATATTTCACGGTGCCTGAAAA }\end{array}$ & 43 & Wasfi et al. (2016) \\
\hline entB & $\begin{array}{l}\text { F CTGCTGGGAAAAGCGATTGTC } \\
\text { R AAGGCGACTCAGGAGTGGCTT }\end{array}$ & 49 & \\
\hline trat & $\begin{array}{l}\text { F GGTGTGGTGCGATGAGCACAG } \\
\text { R CACGGTTCAGCCATCCCTGAG }\end{array}$ & 55 & El Fertas-Aissani et al. (2013) \\
\hline$r m p A$ & $\begin{array}{l}\text { F ACTGGGCTACCTCTGCTTCA } \\
\text { R CTTGCATGAGCCATCTTTCA }\end{array}$ & 53 & Siu et al. (2011) \\
\hline $\begin{array}{l}\text { ybts } \\
\text { magA }\end{array}$ & $\begin{array}{l}\text { F GACGGAAACAGCACGGTAAA } \\
\text { R GAGCATAATAAGGCGAAAGA } \\
\text { F GGTGCTCTTTACATCATTGC } \\
\text { R GCAATGGCCATTTGCGTTAG }\end{array}$ & 60 & Compain et al. (2014) \\
\hline htrA & $\begin{array}{l}\text { F AGAGTTCGCCGTTTTGCCAGGG } \\
\text { R ATCAGAGCGCGGATCTTTGCCG }\end{array}$ & 60 & Rasheed et al. (2016) \\
\hline $16 \operatorname{SrRNA}$ & $\begin{array}{l}\text { F AGCCGACCTGAGAGGGTGA } \\
\text { R TCTGGACCGTGTCTCAGTTCC }\end{array}$ & 55 & Marroquin et al. (2019) \\
\hline
\end{tabular}


Then, each well was washed using PBS and adherent cells were scraped off using LB broth. Subsequently, the total RNA of collected strains were extracted using an RNA extraction kit (Qiagen, USA) according to instruction protocol. Using cDNA synthesis kit (Fermentase, Lithuania), the purified RNA was converted to complementary DNA (cDNA). In order to perform the Real-Time PCR, each cDNA was used as a template in $20 \mu$ final volume containing $2 \mu \mathrm{l}$ cDNA, $10 \mathrm{pmol}$ of each primer (Table 1 ), and $10 \mu$ l Power SYBR Green PCR Master Mix (Applied Biosystems) using Bioneer Real-Time PCR equipment (Korea). The $16 S$ rRNA was used as a housekeeping gene to normalize the levels of mRNA expression and the relative expression of $A c r A B$ efflux pump gene was calculated using $\Delta \Delta$ C T method (Vuotto et al. 2017; Fang et al. 2021).

\section{Molecular typing of $K$. pneumoniae strains}

Molecular typing of $K$. pneumoniae strains were done using the repetitive element sequence-based PCR (repPCR) method. The rep-PCR was performed using two following primers: Forward: REP1 5'- III ICG ICG ICA TCI GGC-3' Reverse: REP2 5'- ICG ICT TATCIG GCC TAC $-3^{\prime}$ as described previously. To study the PCR product, electrophoresis was used on $1.5 \%$ agarose gel and the gel was stained with red safe and DNA bands were studied in Geldoc system. Finally, the pattern of DNA bands and their size were examined by Image Lab 4.0 software. The obtaining results were analyzed by gel compare II software using Dice correlation coefficient and the UPGMA (unweighted pair group method with arithmetic mean) method (Hassan and Belal 2016).

\section{Statistical analysis}

All tests used in this study were done in triplicate and the one-way ANOVA test was used for statistical analysis and $p<0.05$ was considered significant.

\section{Results}

Isolation and antimicrobial susceptibility pattern of $K$. pneumoniae strains

A total of $100 \mathrm{~K}$. pneumoniae strains were isolated from 505 clinical samples. These isolates were recovered from specimens of urine $(n=70)$, blood $(n=20)$, Sputum $(n=6)$ and cerebrospinal fluid (CSF, $n=4)$ based on routine microbiological methods. Among 100 clinical strains of K. pneumoniae, 75 (75\%), 73 (73\%) and 68 (68\%) of strains were resistant to ciprofloxacin, Trimethoprimsulfamethoxazole and Nitrofurantoin, respectively and 28 (28\%), 52 (52\%) strains were susceptible to streptomycin and imipenem, respectively (Table 2). In addition, 92 (92\%) strains revealed MDR phenotypes and most MDR strains were resistant to imipenem, meropenem and beta-lactam antibiotics. The studied strains were categorized into 25 antimicrobial-resistant patterns (Table 2).

\section{Phenotypic detection of biofilm formation and efflux pump}

Phenotypic detection of biofilm formation was performed using Congo red agar test and our results showed that $77 \%$ (77 strains) of isolates exhibited black colonies, which presumably indicate biofilm formation (Fig. 1A). The other strains formed white colonies which reflecting no biofilm formation. Moreover, the Cartwheel results

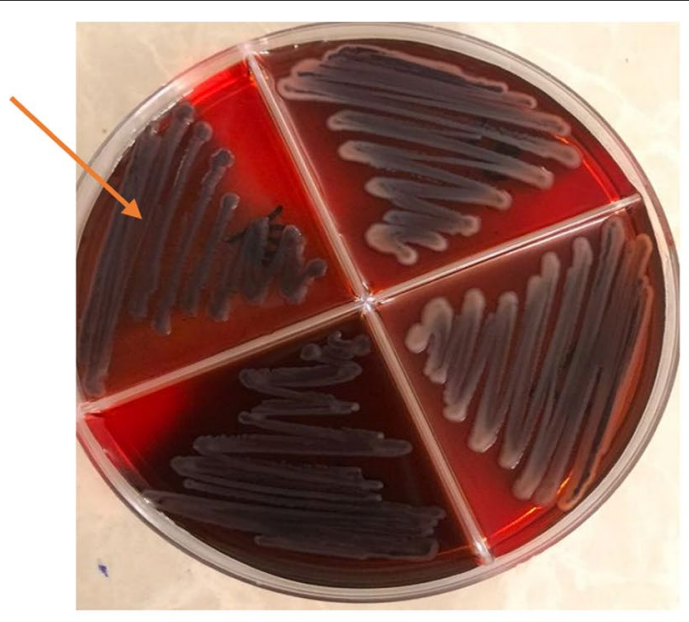

A

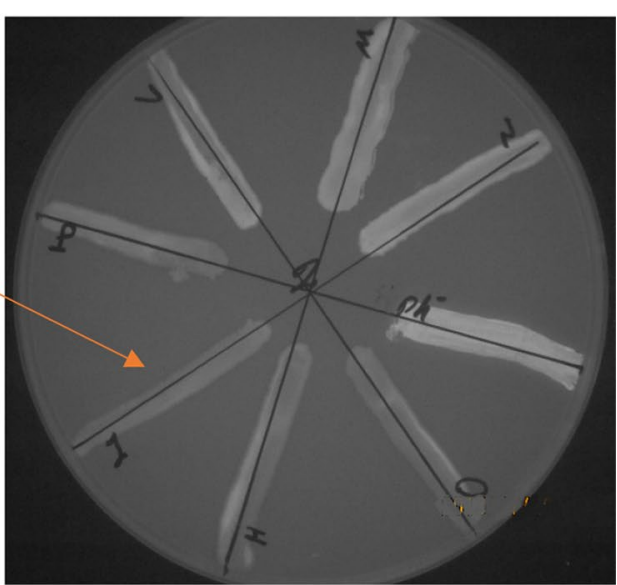

B

Fig. 1 Congo red agar (A) and Cartwheel tests (B) for detection of biofilm producers and efflux pump system in K. pneumoniae strains. As expected, the biofilm forming bacteria exhibited the black appearance in their colonies (Arrow). Moreover, the isolates containing efflux pump did not show fluorescent emission under UV transilluminator (Arrow) 
Table 2 Antimicrobial sensitivity, biofilm formation and efflux pump patterns of K. pneumoniae strains

\begin{tabular}{|c|c|c|c|c|c|c|}
\hline Isolates code & Antibiotic resistant pattern & Anti-biotype (AB) & MDR & $\begin{array}{l}\text { Biofilm } \\
\text { former }\end{array}$ & $\begin{array}{l}\text { Quantitative } \\
\text { biofilm } \\
\text { formation }\end{array}$ & $\begin{array}{l}\text { Phenotypic } \\
\text { efflux pump }\end{array}$ \\
\hline K10, K17, K23, K73, K92, K98 & $\begin{array}{l}\text { CTX, CAZ, CRO, FOX, NA, CP, FM, TE, } \\
\text { S, GM }\end{array}$ & $A B 1$ & + & + & $2.63 \pm 0.14$ & + \\
\hline $\mathrm{K} 15, \mathrm{~K} 20$ & CTX, CAZ, CRO, FOX, NA, CP, FM, TMP & AB2 & + & - & $0.025 \pm 0.03$ & + \\
\hline $\mathrm{K} 1, \mathrm{~K} 6, \mathrm{~K} 13, \mathrm{~K} 25$ & CTX, CAZ, CRO, FOX, TMP, GM, S & $A B 3$ & + & + & $2.13 \pm 0.19$ & + \\
\hline K4, K12, K21, K74, K77, K94 & CAZ, FOX, FM, TE, TMP, S & $A B 4$ & + & + & $3.52 \pm 0.21$ & + \\
\hline K18, K35, K49 & CTX, CAZ, CRO, FOX, FM, TMP & AB 5 & + & + & $0.76 \pm 0.06$ & + \\
\hline K3, K16, K22 & $\mathrm{CTX}, \mathrm{CAZ}, \mathrm{CRO}, \mathrm{NA}, \mathrm{CP}$ & $A B 6$ & + & + & $0.38 \pm 0.08$ & + \\
\hline K8, K45, K75 & CTX, CAZ, CRO, FOX, NA, CP, FM, TE & $A B 7$ & + & + & $2.69 \pm 0.17$ & + \\
\hline K5, K41, K76 & $\begin{array}{l}\text { CTX, CAZ, CRO, FOX, NA, CP, AMC, CF, } \\
\text { S, FM, TMP, IMP, GM, MEN }\end{array}$ & $A B 8$ & + & + & $3.4 \pm 0.12$ & + \\
\hline K19, K31, K72 & CTX, CAZ, CRO, NA, CP, FM, TMP, GM, S & AB 9 & + & + & $1.8 \pm 0.07$ & - \\
\hline K7 & $\mathrm{AMC}, \mathrm{S}, \mathrm{CF}, \mathrm{TMP}$ & $A B 10$ & + & + & $0.17 \pm 0.16$ & + \\
\hline $\mathrm{K} 9, \mathrm{~K} 28, \mathrm{~K} 87$ & $\begin{array}{l}\text { FM, CF, AMC, K, GM, TMP, CP, AN, FOX, } \\
\text { CTX, CRO, CAZ }\end{array}$ & $A B 11$ & + & + & $0.81 \pm 0.007$ & + \\
\hline K24, K26, K40 & S, CF, AMC, FM, IPM, TMP, MEN, NA, CP & $A B 12$ & + & - & $0.16 \pm 0.003$ & + \\
\hline K14, K39 & $\begin{array}{l}\mathrm{CL}, \mathrm{TE}, \mathrm{PB}, \mathrm{AN}, \mathrm{TMP}, \mathrm{GM}, \mathrm{K}, \mathrm{S}, \mathrm{FM}, \mathrm{AMC} \text {, } \\
\mathrm{CF}\end{array}$ & AB 13 & + & + & $0.15 \pm 0.006$ & + \\
\hline K41, K59, K61, K93 & $\mathrm{AMC}, \mathrm{CF}, \mathrm{FM}, \mathrm{PB}, \mathrm{CL}, \mathrm{TE}$ & $A B 14$ & + & + & $0.94 \pm 0.007$ & - \\
\hline K36, K43 & $C P, T E, N A, F M, M E N, T M P, C F, A M C$ & $A B 15$ & + & + & $0.16 \pm 0.006$ & + \\
\hline K53, K81, K96 & CF, AMC, MEN, TMP, IPM, CP, NA & AB 16 & + & + & $0.20 \pm 0.13$ & + \\
\hline K27, K30, K62, K88 & $\begin{array}{l}\text { FM, AMC, CF, IPM, AN, MEN, GM, TMP, } \\
\text { CP, TE, NA, CL }\end{array}$ & AB 17 & + & + & $0.19 \pm 0.001$ & + \\
\hline $\mathrm{K} 2, \mathrm{~K} 11, \mathrm{~K} 60, \mathrm{~K} 78, \mathrm{~K} 100$ & $C F, A M C, T M P, C P, T E, N A$ & AB 18 & + & + & $0.13 \pm 0.006$ & + \\
\hline K50, K80, K85, K86 & $\begin{array}{l}\text { AMC, FM, CF, CP, TE, NA, MEN, IPM, TMP, } \\
\text { GM, AN }\end{array}$ & AB 19 & + & + & $2.13 \pm 0.003$ & + \\
\hline K48, K52, K58, K65 & AMC, S, CF, FM, IPM, MEN, CP, NA & AB 20 & + & + & $3.82 \pm 0.009$ & + \\
\hline K33, K47, K71, K56, K83, K69 & $\begin{array}{l}\text { CF, K, FM, AMC, GM, MEN, IPM, AN, } \\
\text { TMP, NA, TE, CP }\end{array}$ & AB 21 & + & + & $0.19 \pm 0.007$ & + \\
\hline K 34, K 42, K 99 & AMC, CF, FM, IMP, MEN, TMP, CP, NA, TE & AB 22 & + & + & $1.45 \pm 0.008$ & - \\
\hline $\begin{array}{l}\mathrm{K} 44, \mathrm{~K} 50, \mathrm{~K} 54, \mathrm{~K} 7, \mathrm{~K} 66, \mathrm{~K} 79, \mathrm{~K} 97, \mathrm{~K} 63 \\
\mathrm{~K} 64, \mathrm{~K} 70, \mathrm{~K} 82\end{array}$ & $\begin{array}{l}\text { CAZ, CRO, FOX, K, FM, AMC, CF, AN, } \\
\text { TMP, GM, IMP, MEN, CP, TE, NA }\end{array}$ & AB 23 & + & - & $0.02 \pm 0.002$ & + \\
\hline K 29, K 32, K 51, K 55, K 57, K 68, K 84 & $\begin{array}{l}C P, T E, N A, T M P, G M, I M P, M E N, A M C \\
F M, C F, C A Z, C T X, C R O, F O X\end{array}$ & AB 24 & + & - & $0.029 \pm 0.001$ & + \\
\hline $\begin{array}{l}\text { K } 30, \text { K } 89, \text { K 90, K 91, K } 37, \text { K } 38, \text { K 46, } \\
\text { K } 95\end{array}$ & $C F, A M C$ & AB 25 & - & + & $0.56 \pm 0.001$ & + \\
\hline
\end{tabular}

CF Chloramphenicol, AMC Amoxicillin-clavulanic acid, FOX Cefoxitin, CRO Cefteriaxon, CTX Cefotaxime, CAZ Ceftazidime, FM Nitrofurantoin, MEN Meropenem, IMP Imipenem, GM Gentamycin, TMP Trimethoprim-sulfamethoxazole, NA Nalidixic acid, TE Tetracycline, CP Ciprofloxacin, S Streptomycin, K Kanamycin, $C L$ Clindamycin, PB Polymixin B, S Streptomycin

showed that $90 \%$ (90 isolates) of strains had efflux pumps (Fig. 1B).

\section{Quantitative biofilm production}

The results of the quantitative biofilm production test are shown in Table 2 as mean OD 570 values. According to OD values among $77 \%$ biofilm producers, 50 isolates $(71 \%)$ were categorized as strong biofilm former (OD > 0.204), $16(20 \%)$ as moderate biofilm former $(0.102<\mathrm{OD}<0.204)$ and 11 isolates $(14 \%)$ as weak biofilm former $(0.0551<\mathrm{OD}<0.102)$. There is a significant between MDR phenotype, biofilm formation, and efflux pump among $K$. pneumoniae strains $(p<0.05)$. Moreover, there was a significant correlation between biofilm formation in isolates recovered from urine comparing to other type specimens $(p<0.05)$.

\section{Frequency of biofilm, efflux pump and virulence associated genes}

The prevalence of biofilm, efflux pump and virulenceassociated genes are given in Additional file 1: Table S1. The $m r k A, m r k D$ and $f i m H$ genes encoding type 1 and 
type 3 fimbrial adhesion engaged in biofilm formation were present in all biofilm former strains. Prevalence of biofilm-associated genes including $m r k A$, fimH, and $m r k D$ were equally $88 \%$ for all tested. Moreover, the efflux pump genes including acrAB, tolC and $m d t K$ were observed in 41 (41\%), 33 (33\%) and $26(26 \%)$ of the strains, respectively. The $\operatorname{acr} A B$ was more prevalent in $K$. pneumoniae strains comparing to other efflux pump genes. In addition, the $a c r A B$ efflux pump gene was more prevalent in urine samples in comparison to other clinical specimens. In addition, the virulence-related genes including enterobactin biosynthesis gene (entB), outer membrane protein-coding gene (traT), yersiniabactin biosynthesis gene (ybts), mucoviscosity-associated gene $A(\operatorname{mag} A)$, iron siderophores aerobactin synthase gene (iucC),periplasmic serine endoprotease DegP-like (htrA) and mucoid phenotype A $(r m p A)$ were found in 80 (80\%), 62 (62\%), 75 (75\%), 5 (5\%), 30 (30\%), 72 (72\%) and $48(48 \%)$, of the isolates, respectively. As reported in Additional file 1: Table S1, analysis of selected genes showed that biofilm was more pronounced among virulence-associated gene-positive than among negative strains. The ent $B$ virulence gene was detected in all blood, CSF, and sputum isolates. There were 8 virulence profiles (V1-V8) based on detected virulence gene and V1 was the most prevalent virulence type. It should be noted that the virulence genetic profiles showed that the virulence determinants vary between the strains of $K$. pneumoniae that have the same source.

\section{$a c r A B$ efflux pump and $m r k A$ biofilm gene expression}

The eight MDR (K1, K6, K10, K13, K17, K18, K23 and K25 isolates) and non-MDR (K30, K37, K38, K46, K89, K90, K91 and K95 isolates) K. pneumoniae strains were selected for acr $A$ and $m r k A$ gene expression analysis. The results of Real-Time PCR showed that $\operatorname{acr} A$ and $m r k A$ genes were up-regulated significantly in MDR isolates comparing to non-MDR isolates

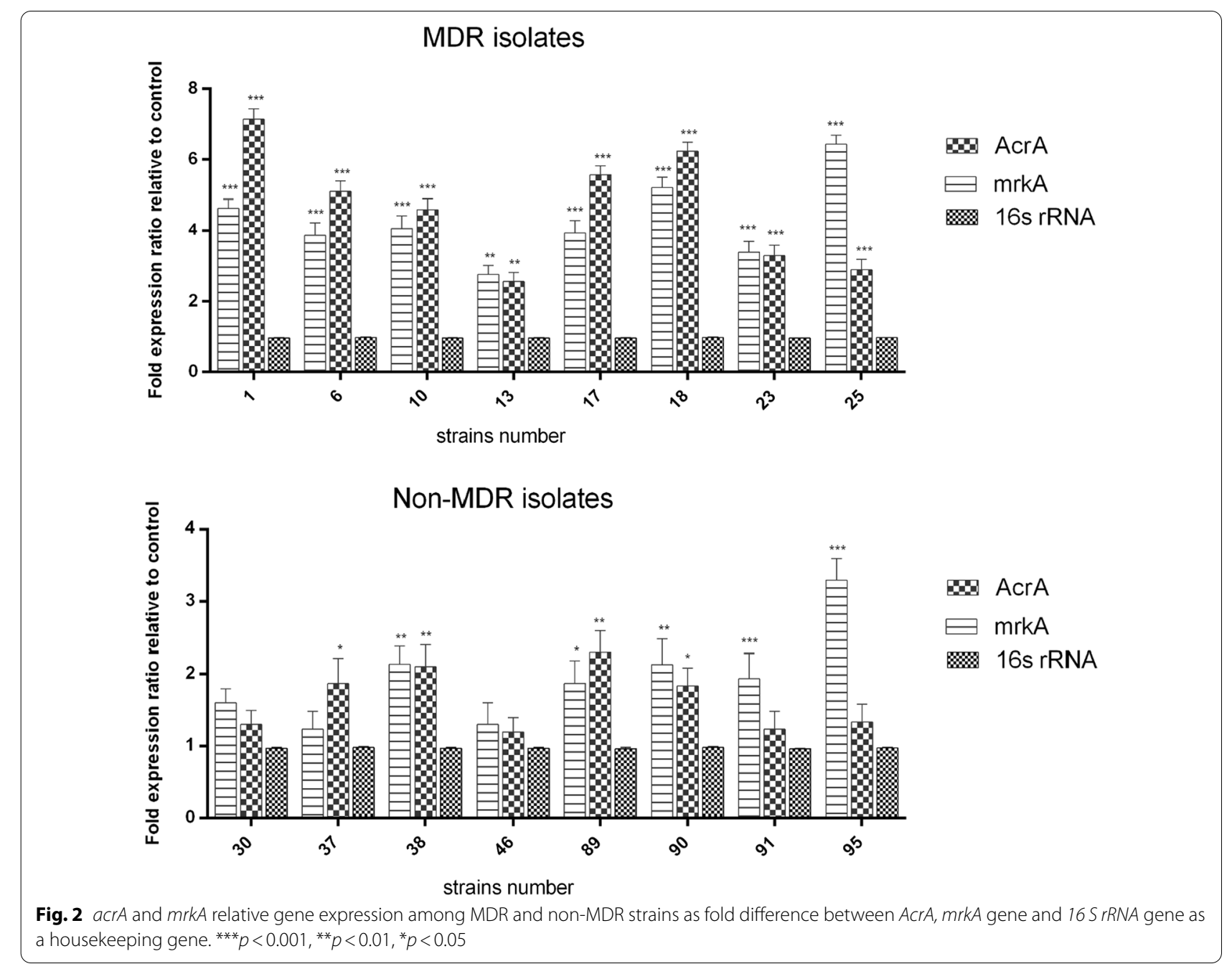


(Fig. 2). Amplification plot and melting curve analysis were used to confirm the amplification of the desired genes (Fig. 3A, B).There was a significant relationship between MDR isolates, acr $A$, and $m r k A$ gene expression $(p<0.05)$.

\section{Rep-PCR typing}

According to the dendrogram, Repetitive element sequence-based PCR (rep-PCR) revealed 11 distinct patterns of $K$. pneumoniae isolates (Additional file 1: Figure $\mathrm{S} 1$ and Fig. 4). The 11 rep genotypes were designed as rep 1 to rep 11 . The rep type $4-7$ were the most common
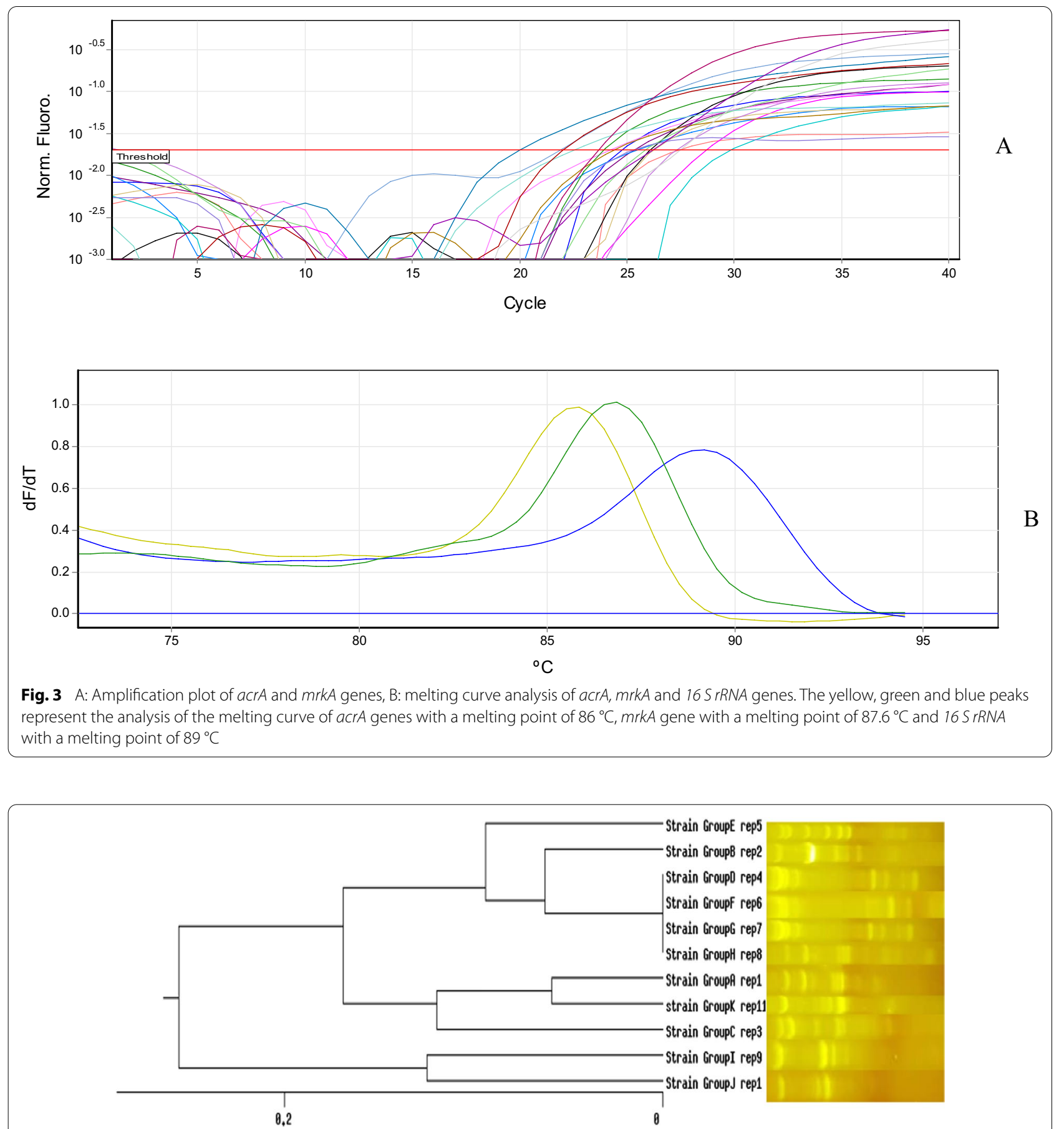

Fig. 4 The rep-PCR of representative K. pneumoniae strains using the UPGMA based on Dice similarity. Showed 11 rep-types 
followed by type rep 1, 9, and 3, which consisted of nonMDR isolates (Group I: K30, K95, K90, K91, Group C: K37, K89, Group J: K38 and K46). The rep type 11 was unique and contained one strain exclusively. Based on statistical correlation tests, the rep type 2, 4, 5, 6 and 7 had significantly correlation with MDR strains and virulence patterns $(p<0.05)$. The strains showed high similarity which may suggest that those isolates consist of a clonal lineage $(p<0.05)$.

\section{Discussion}

Multidrug-resistant (MDR) K. pneumoniae strains are amongst the most important cause of several life-treating infections, worldwide (Ghafourian et al. 2011). The extensive use of antimicrobial agents led to a high prevalence of MDR K. pneumoniae strains (Ciccozzi et al. 2019). The increasing rate of $K$. pneumoniae strains resistant to multiple antimicrobials is a global public health problem (Khandelwal et al. 2019). In this study, the prevalence of MDR K. pneumoniae isolates was $92 \%$. The high rate of MDR strains has been shown in other studies. Manjula et al., indicated that $90.2 \%$ of isolates were MDR and the majority of MDR strains were resistant to a high range of antibiotics including penicillin, cephalosporin, fluoroquinolone, aminoglycoside, and sulfonamide (Manjula et al. 2014). Moreover, $48 \%$ and $47 \%$ of $K$. pneumoniae strains were resistant to imipenem and meropenem, respectively. Yang et al. reported that the highest multidrug resistance rate was detected in human strains of $K$. pneumoniae strains (90.4\%). Highest resistance to imipenem $38 \%(34 / 89)$, meropenem $31 \%(n=28 / 89)$ among K. pneumoniae strains was reported by Indrajitha et al. (2021) which is less than the resistance rates seen in our K. pneumoniae strains.

From the results, it can be concluded that there has been a significant increase in carbapenem resistant $K$. pneumoniae isolates in Iran. It seems that the production of carbapenemase and metallobetalactamase have an important role in carbapenems resistance (DuranteMangoni et al. 2019).

One of the possible reasons for the high rate of antimicrobial resistance is the lack of strict policies for use of antibiotics in Iran. Another mechanism of multidrugresistant is efflux pumps which are used by $K$. pneumoniae strains (Maurya et al. 2019). The efflux pumps could reduce the intracellular concentration of antibiotics which is an important cause of bacterial survival (Xu et al. 2019). In our study, the AcrAB efflux pump was the most common efflux pump in K. pneumoniae strains comparing to $m d t k$. It was significantly correlated with MDR phenotype. Our results are consistent with other reports which indicated that the multidrug efflux pump system (AcrAB-TolC) in K. pneumoniae strains is responsible for antibiotics especially fluoroquinolones such as ciprofloxacin, tetracycline and beta-lactam antibiotics in MDR isolates. In addition, our results showed that $77 \%$ of $K$. pneumoniae strains were able to form biofilm and $89 \%$ of biofilm former were MDR. Nirwati et al. showed that $148(85.63 \%)$ of their isolates were biofilm producers, with $45(26.95 \%)$ isolates as strong, 48 $(28.74 \%)$ isolates as moderate, and $50(29.94 \%)$ isolates as weak biofilm producers. Shadkam et al., using the tissue culture plate assay demonstrated that $75(75 \%)$ of the strains could form a biofilm and $25 \%$ of the strains did not have the ability to form a biofilm. The results of Karimi et al. (2021) indicated that Biofilm formation was seen in 62 (75\%) of K. pneumoniae strains. Strong biofilm formation was observed in 17 (20\%) strains and a significant correlation was seen between biofilm formation and antibiotic resistance $(p<0.05)$. Comparison of the results of our study and the other studies indicated that a high percentage of $K$. pneumoniae strains can form biofilms.

Until now, it has been shown that there is a significant correlation between MDR phenotype and the biofilmforming ability of $K$. pneumoniae strains (Ostria-Hernandez et al. 2018). In addition, the relationship between biofilm formation and antibiotic resistance in K. pneumoniae strains at high concentrations, especially sub-inhibitory, has been studied (Maharjan et al. 2018). There was a significant correlation between urine $K$. pneumoniae strains and biofilm formation. Most of the urine- originated strains exhibited strong biofilm capacity.

In the current study, K. pneumoniae strains recovered from the clinical samples harbored a high prevalence of efflux pump, biofilm and virulence associated genes. The virulence associated genes were also dominant in MDR strains. Type 1 fimbriae (fimH-1) and Type 3 fimbrial adhesion ( $m r k A$ and $m r k D$ ) are the most common bacteria cells adhesive agent which causes $K$. pneumoniae to attach to epithelial and endothelial cells of the urinary tract and causes urinary tract infection (Ranjbar et al. 2007; Panjaitan et al. 2019). Studies have shown that type 3 fimbrial adhesion plays a very important role in biofilm formation in K. pneumoniae, but its exact mechanism has not yet been identified (Khalil et al. 2019). Nirwati and colleagues studied the rate of biofilm formation in K. pneumoniae strains, and the results of their study showed that $85.63 \%$ of the strains constituted biofilm, which was higher than the results of our study (Nirwati et al. 2019). In our study, the fimH, $m r k A$ and $m r k D$ were detected in all types of urine, blood and CSF isolates. The enterobactin biosynthesis gene (entB), serum resistanceassociated outer membrane lipoprotein (traT) and regulators of mucoid phenotype A $(r m p A)$ were detected in $80 \%, 62 \%$ and $48 \%$ of $K$. pneumonia strains. The traT gene encodes an outer membrane protein which plays an 
important role in conjugation and inhibition of complement cascade and acts as invasin (Kuş et al. 2017). Wasfi et al. showed that the aerobactin synthase gene (IucC), enterobactin biosynthesis gene (entB) and Yersinibactin biosynthesis gene (Irp-1) were detected in $32.14 \%$, 85.7\% and $28.5 \%$ of MDR K. pneumoniae isolates, respectively. Ranjbar et al. demonstrated that fimH-1 (93.04\%), traT (92.17\%), mrkD (84.34\%), and entB (80.86\%) were the most commonly detected virulence genes in K. pneumoniae strains. Alcántar-Curiel et al. (2013) showed that the $m r k D$ adhesin gene and fimH were present in $14 / 69$ $(20 \%)$ and $54 / 69(78 \%)$ of strains. The results of virulence gene prevalence in various studies have been close to our results, which indicates the high prevalence of virulence genes in K. pneumoniae strains. In addition, the results of Real-Time PCR showed that acrA and $m r k A$ genes were up-regulated significantly in MDR isolates comparing to non-MDR isolates which consistent to another repots. Vuotto et al., Showed that $m r k A$ genes was upregulated in biofilm-grown MDR K. pneumoniae strains (Vuotto et al. 2017).

Molecular typing is a useful method for the differentiation of nosocomial infections and rep-PCR is a widely used genotyping tool for bacterial strains (Rojas et al. 2017). In our study, out of $100 \mathrm{~K}$. pneumoniae strains, rep-PCR differentiated the strains into 11 distinct patterns and most MDR strains were put in the same patterns. Our data confirmed the Lai et al. results which showed pathogenic $K$. pneumoniae strains are heterogeneous, because of variation in genome sequences (Lai et al. 2000). Our results showed the correlation of MDR strains with rep-PCR patterns. However, the rep-PCR revealed no statistically significant correlation with virulence type. In addition, the rep-PCR results showed that the same rep-type in two studied hospitals indicating the same clonal distribution of $K$. pneumoniae in two hospitals. Our findings can be useful for the interpretation of MDR K. pneumoniae outbreaks associated with specific patterns in the future. Ghasemian et al. (2017) investigated the rep-PCR analysis for the fingerprinting of $K$. pneumonia isolates. Their results showed that $K$. pneumonia strains placed in 6 clusters and a similarity of $90 \%$ was observed among $50-80 \%$ of isolates. In Austria in 2010, Grisold et al. investigated a rep-PCR and pulsed field gel electrophoresis (PFGE) methods for the molecular typing of isolated $K$. oxytoca-producing $\beta$-lactamase. The results of the automatic rep-PCR method, compared to PFGE, were more accurate for studying the prevalence of isolated $K$. oxytoca-producing $\beta$-lactamase with a wider range (Grisold et al. 2010).

In our study, we reported the high prevalence of MDR K. pneumoniae strains with resistance to multiple antimicrobial agents, the ability to form biofilm and the presence of efflux pump, biofilm and virulence-associated genes which can be a considered as a major challenge for treatment of $K$. pneumoniae related infections and further spread of resistance genes to other regions. Moreover, high levels of genetic similarity between MDR strains in hospitals showed clonal dissemination of $K$. pneumoniae strains that requires control tools. However, further studies are needed to show other epidemiological aspects of the K. pneumoniae strains in our country.

\section{Supplementary Information}

The online version contains supplementary material available at https://doi. org/10.1186/s13568-021-01282-w.

Additional file 1: Table S1. Biofilm, efflux pump and virulenceassociation genes among K. pneumoniae strains. Figure S1.The rep-PCR fingerprints of K. pneumoniae strains. Lane 6, 16: 100bp+Ladder. Lane 1: rep 3, Lane 3: rep 9, Lane 4: rep 6, lane 5: negative control,Lane 7: rep 5, Lane 10, 12: rep 7, Lane 11: rep 8, Lane 13: rep 4, lane 15, 18:rep 1, Lane 19, 17: rep 2.

\section{Acknowledgements}

Research reported in this publication was supported by a grant provided from the Ministry of Health and Medical Education and Iran National Science Foundation (INSF), Tehran, Iran. The authors would like to acknowledge the Ministry of Health and Medical Education and INSF. The authors would like also to thank the Clinical Research Development Unit of Baqiyatallah Hospital, Tehran, Iran, for guidance and advice.

\section{Authors' contributions}

RR conceived and designed the experiments. AA performed the experiments, analyzed the results, done the statistical analyses and wrote the manuscript. All authors read and approved the final manuscript.

\section{Funding}

This study was supported by a grant provided from the Ministry of Health and Medical Education and INSF, Tehran, Iran.

\section{Availability of data and materials}

All data generated or analyzed during this study are included in this manuscript.

\section{Declarations}

Ethics approval and consent to participate

This study was done in Molecular Biology Research Center, Baqiyiatallah University of Medical Sciences as an original research project (code: 91002439). The project was ethically approved by the ethic committee of Baqiyiatallah University of Medical Sciences, Tehran, Iran. Informed consent was obtained from all patients included.

Consent for publication

Not applicable.

\section{Competing interests}

No competing interests.

Received: 8 May 2021 Accepted: 18 August 2021

Published online: 30 August 2021 


\section{References}

Alcántar-Curiel MD, Blackburn D, Saldaña Z, Gayosso-Vázquez C, lovine N, De la Cruz MA (2013) Multi-functional analysis of Klebsiella pneumoniae fimbrial types in adherence and biofilm formation. Virulence 4(2):129-138

Alharthi A, Gaber A, Hassan MM (2016) Molecular characterization of mecA and SCCmec genes in pathogenic Staphylococcus spp. collected from hospitals in Taif region, KSA. Biotech 15:26-34

Alkhudhairy MK, Alshadeedi SMJ, Mahmood SS, Al-Bustan SA, Ghasemian A (2019) Comparison of adhesin genes expression among Klebsiella oxytoca ESBL-non-producers in planktonic and biofilm mode of growth, and imipenem sublethal exposure. Microb Pathog 134(2):103558

Behdad R, Pargol M, Mirzaie A, Karizi SZ, Noorbazargan H, Akbarzadeh I (2020) Efflux pump inhibitory activity of biologically synthesized silver nanoparticles against multidrug-resistant Acinetobacter baumannii clinical isolates. J Basic Microbiol 60(6):494-507

Ciccozzi M, Cella E, Lai A, De Florio L, Antonelli F, Fogolari M, Di Matteo FM, Pizzicannella M, Colombo B, Dicuonzo G, Angeletti S (2019) Phylogenetic analysis of multi-drug resistant Klebsiella pneumoniae strains from Duodenoscope biofilm: microbiological surveillance and reprocessing improvements for infection prevention. Front Public Health 7(2):219-229

Collee J (2007) In: Collee JG, Fraser AG, Marimon BP, Simmons A, editors. Mackie \& Mccartney practical medical microbiology. Elsevier

Compain F, Babosan A, Brisse S, Genel N, Audo J, Ailloud F (2014) Multiplex PCR for detection of seven virulence factors and K1/K2 capsular serotypes of Klebsiella pneumoniae. J Clin Microbiol 52(12):4377-4380

Donelli G, Vuotto C, Cardines R, Mastrantonio P (2012) Biofilm-growing intestinal anaerobic bacteria. FEMS Immunol Med Microbiol 65(2):318-325

Durante-Mangoni E, Andini R, Zampino R (2019) Management of carbapenem-resistant Enterobacteriaceae infections. Clin Microbiol Infect 25(8):943-950

El Fertas-Aissani R, Messai Y, Alouache S, Bakour R (2013) Virulence profiles and antibiotic susceptibility patterns of Klebsiella pneumoniae strains isolated from different clinical specimens. Pathol Biol (Paris) 61(1):209-216

Fang R, Liu H, Zhang X, Dong G, Li J, Tian X (2021) Difference in biofilm formation between carbapenem-resistant and carbapenem-sensitive Klebsiella pneumoniae based on analysis of $\mathrm{mrkH}$ distribution. Microb Pathog 152:104743

Freeman DG, Falkiner FR, Keane CT (1989) New method for detecting slime production by coagulase negative staphylococci. J Clin Pathol 42(8):872-874

Fuzi, M., Rodriguez Baño, J., Toth, A. (2020). Global evolution of pathogenic bacteria with extensive use of fluoroquinolone agents. Front Microbiol 11(1): 271. Published online 2020 Feb 25. doi: https://doi.org/10.3389/ fmicb.2020.00271.

Ghafourian S, Bin Sekawi Z, Sadeghifard N, Mohebi R, Neela K, Maleki V, Hematian A, Rhabar A, Raftari M, Ranjbar M, R (2011) The prevalence of ESBLs producing Klebsiella pneumoniae isolates in some major hospitals, Iran. Open Microb J 5(1):91-95

Ghasemian A, Nojoomi F, Eslami M (2017) The rep-PCR typing of TEM type ESBL producing clinical isolates of Klebsiella pneumonia. MOJ Cell Sci Rep 4(4):98-102

Grimsey EM, Fais C, Marshall RL, Ricci V, Ciusa ML, Stone JW, Ivens A, Malloci G, Ruggerone P, Vargiu AV, Piddock LJV (2020) Chlorpromazine and amitriptyline are substrates and inhibitors of the AcrB multidrug efflux pump. mBio 11(3):e00465-e00420

Grisold AJ, Zarfel G, Strenger V, Feierl G, Leitner E, Masoud L, Hoenigl M, Raggam RB, Dosch V, Marth E (2010) Use of automated repetitive-sequencebased PCR for rapid laboratory confirmation of nosocomial outbreaks. J Infect 60(1):44-51

Hasan ME, Shahriar A, Shams F, Nath AK, Emran TB (2020) Correlation between biofilm formation and antimicrobial susceptibility pattern toward extended spectrum $\beta$-lactamase (ESBL)- and non-ESBL-producing uropathogenic bacteria. J Basic Clin Physiol Pharmacol 23(1):12-21

Hassan M, El-Sayed B, Belal (2016) Antibiotic resistance and virulence genes in Enterococcus strains isolated from different hospitals in Saudi Arabia. Biotechnol Biotechnol Equip 30(4):726-732

Heidary M, Nasiri MJ, Dabiri H, Tarashi S (2018) Prevalence of drug-resistant Klebsiella pneumoniae in Iran: a review article. Iran J Public Health 47(3):317-326

Highsmith AK, Jarvis WR (1985) Klebsiella pneumoniae: selected virulence factors that contribute to pathogenicity. Infect Control 6(2):75-77
Indrajitha S, Kumar Mukhopadhyay A, Chowdhury G, Farraj DAA, Alkufeidy M, R (2021) Molecular insights of carbapenem resistance Klebsiella pneumoniae isolates with focus on multidrug resistance from clinical samples. J Infect Public Health 14(1):131-138

Jafari Z, Harati AA, Haeili M, Kardan-Yamchi J, Jafari S, Jabalameli F (2019) Molecular epidemiology and drug resistance pattern of carbapenemresistant Klebsiella pneumoniae isolates from Iran. Microb Drug Resist 25(3):336-343

José A, Bengoechea., Joana Sa, Pessoa. (2019). Klebsiella pneumoniae infection biology: living to counteract host defences. FEMS Microbiol Rev 43(2): $123-144$.

Karimi K, Zarei O, Sedighi P, Taheri M, Doosti-Irani A, Shokoohizadeh L (2021) Investigation of antibiotic resistance and biofilm formation in clinical isolates of Klebsiella pneumoniae. InterJ Microbiol Article ID 5573388

Khalil MAF, Hager R, Abd-El Reheem F, Mahmoud EE, Samir T, Moawad SS, Hefzy EM (2019) A study of the virulence traits of carbapenem-resistant Klebsiella pneumoniae isolates in a Galleria mellonella Model. Microb Drug Res 25(7):1063-1071

Khandelwal V, Sharma S (2019) Fatal MDR Klebsiella in ICU—how was it dealt with? Indian J Crit Care Med 23(9):411-413

Kuş H, Arslan U, Türk Dağı H, Fındık D (2017) Investigation of various virulence factors of Klebsiella pneumoniae strains isolated from nosocomial infections. Mikrobiyol Bul 51(4):329-339

Lai Y, Yang C, Peng SL, Chang HL H, Y (2000) Identification of genes present specifically in a virulent strain of Klebsiella pneumoniae. Infect Immun 68(1):7149-7151

Maharjan G, Khadka P, Siddhi Shilpakar G, Chapagain G, Dhungana GR (2018) Catheter-associatedurinary tract infection and obstinate biofilm producers. Can J Infect Dis Med Microbiol 26:7624857

Manjula N, Girish C, Math., Nagshetty K, Shripad A, Patil., Subhashchandra M, Gaddad., Channappa T, Shivannavar (2014) Antibiotic susceptibility pattern of ESBL producing Klebsiella pneumoniae isolated from urine samples of pregnant women in Karnataka. J Clin Diagn Res 8(10):DC08-DC11

Marroquin S, Brittney G, Brooke T, Michelle S, Frey A, Rebecca A, Keogh., Rachel Z, Daniel A, Todd., Nadja B, Cech., Ronan K, Carroll., Lindsey N, Shaw (2019) MroQ is a novel Abi-Domain protein that influences virulence gene expression in Staphylococcus aureus via modulation of Agr activity. Infect Immun 87(5):e00002-e19

Martins M, Viveiros M, Couto I, Costa SS, Pacheco T, Fanning S, Pagès JM, Amaral L (2011a) Identification of efflux pump-mediated multidrugresistant bacteria by the ethidium bromide-agar cartwheel method. Vivo 25(2):171-178

Martins M, Viveiros M, Couto I, Costa SS, Pacheco T (2011b) Identification of efflux pump mediated multidrug-resistant bacteria by the ethidium bromide-agar cartwheel method. In Vivo 25:171-178

Maurya N, Jangra M, Tambat R, Nandanwar H (2019) Alliance of efflux pumps with $\beta$-lactamases in multidrug-resistant Klebsiella pneumoniae isolates. Microb Drug Resist 25(8):1155-1163

Montazeri A, Salehzadeh A, Zamani H (2020) Effect of silver nanoparticles conjugated to thiosemicarbazide on biofilm formation and expression of intercellular adhesion molecule genes, icaAD, in Staphylococcus aureus. Folia Microbiol (Praha) 65:153-160

Mukherjee S, Bhattacharjee A, Naha S, Majumdar T, Debbarma SK, Kaur H, Dutta S, Basu S (2019) Molecular characterization of NDM-1-producing emopenKlebsiella pneumoniaeemclose ST29, ST347, ST1224, and ST2558 causing sepsis in neonates in a tertiary care hospital of North-East India. Infect Genet Evol 69:166-175

Naha S, Sands K, Mukherjee S, Roy C, Rameez MJ, Saha B, Dutta S, Walsh TR, Basu S (2020) KPC-2-producingKlebsiella pneumoniae ST147 in a neonatal unit: Clonal isolates withdifferences in colistin susceptibility attributed to AcrAB-TolC pump. Int J Antimicrob Agents 55(3):105903

Nirwati H, Kian SFF, Wijaya F, Napitupulu S, Hati VP, Hakim MS, Meliala A, Aman AT, Nuryastuti T (2019) Biofilm formation and antibiotic resistance of emopenKlebsiella pneumoniaeemclose isolated from clinical samples in a tertiary care hospital, Klaten,\&nbsp;Indonesia. BMC Proc 13(Suppl 11):20. https://doi.org/10.1186/s12919-019-0176-7

Ostria-Hernandez ML, Juárez-de la Rosa KC, Arzate-Barbosa P, Lara-Hernández A, Sakai F, Ibarra JA, Castro-Escarpulli G, Vidal JE (2018) Nosocomial, multidrug-resistant Klebsiella pneumoniae strains isolated from Mexico city produce robust biofilms on abiotic surfaces but not on human lung cells. Microb Drug Resist 24(4):422-433 
Panjaitan NSD, Horng YT, Cheng SW, Chung WT, Soo PC (2019) EtcABC, a Putative Ell complex, regulates type 3 fimbriae via CRP-CAMP signaling in Klebsiella pneumoniae. Front Microbiol 10(1):1558-1563

Pasala AR, Perini M, Piazza A, Panelli S, Carlo DD, Loretelli C, Cafiso A, Inglese S, Gona F, Cirillo DM, Zuccotti GV, Comandatore F (2020) Repeatability and reproducibility of the emopenwziemclose high resolution melting-based clustering analysis for emopenKlebsiella pneumoniaeemclose typing. AMB Expr 10:217

Ranjbar R, Sadeghifard N, Ahmadi A, Izadi M, Zaeimi-Yazdi J, Ghasemi A, Qurbanalizadgan M, Rostamzad A (2007) Antimicrobial susceptibility and APPCR typing of Acinetobacter spp. strains. Iranian J Public Health 36:50-56

Ranjbar R, Izadi M, Hafshejani TT, Khamesipour F (2016a) Molecular detection and antimicrobial resistance of Klebsiella pneumoniae from house flies (Musca domestica) in kitchens, farms, hospitals and slaughterhouses. J Infect Public Health 9(4):499-505

Ranjbar R, Memariani H, Sorouri R, Memariani M (2016b) Distribution of virulence genes and genotyping of CTX-M-15-producing Klebsiella pneumoniae isolated from patients with community-acquired urinary tract infection (CA-UTI). Microb Pathog 100:244-249

Ranjbar R, Pezeshknejad P, Khamesipour F, Amini K, Kheiri R (2017) Genomic fingerprints of Escherichia coli strains isolated from surface water in Alborz province, Iran. BMC Res Notes 10(1):295-306

Ranjbar R, Fatahian Kelishadrokhi A, Chehelgerdi M (2019) Molecular characterization, serotypes and phenotypic and genotypic evaluation of antibiotic resistance of the Klebsiella pneumoniae strains isolated from different types of hospital-acquired infections. Infect Drug Resist 12(1):603-611

Rasheed DF, Manhal. FS (2016) Molecular characterization of capsular polysaccharide and putative seine protease gens of Klebsiella pneumoniae isolated from public hospitals in Baghdad, Iraq. World J Pharm Res 5:306-315

Rojas, LJ., Salim, M., Cober, E., Richter, SS., Perez, F., Salata, RA., Kalayjian, RC. Watkins, RR., Marshall, S., Rudin, SD., Domitrovic, TN., Hujer, AM., Hujer, KM., Doi, Y., Kaye, KS., Evans, S., Fowler, VG Jr., Bonomo, RA., van Duin D. (2017). Colistin resistance in carbapenem-resistant Klebsiella pneumoniae: laboratory detection and impact on mortality. Clin Infect Dis 64(6): 711-718.

Sahly H, Navon-Venezia S, Roesler L, Hay A, Carmeli Y, Podschun R, Hennequin C, Forestier C, Ofek I (2008) Extended-spectrum beta-lactamase production is associated with an increase in cell invasion and expression of fimbrial adhesins in Klebsiella Pneumoniae. Antimicrob Agents Chemother 52(9):3029-3034

Sahoo RK, Das A, Gaur M, Pattanayak A, Sahoo S, Debata, NK., Rahman, PKSM., Subudhi, E. (2019). Genotypic validation of extended-spectrum $\beta$-lactamase and virulence factors in multidrug resistance Klebsiella pneumoniae in an Indian hospital. Pathog Glob Health 113(7): 315-321.

Shao, L., Yao, B., Yang, J., Li, X., Ye, K., Zhang, Y., Wang, C. (2020). Characterization of a multidrug-resistant Klebsiella pneumoniae ST3330 clone responsible for a nosocomial outbreak in a neonatal intensive care unit. Ann Palliat Med 9(3): 1092-1102.

Siu LK (2011) Molecular typing and virulence analysis of serotype K1 Klebsiella pneumoniae strains isolated from liver abscess patients and stool samples from noninfectious subjects in Hong Kong, Singapore, and Taiwan. J Clin Microbiol 49:3761-3765

Subramanian P, Shanmugam N, Sivaraman U, Kumar S, Selvaraj S (2012) Antiobiotic resistance pattern of biofilm-forming uropathogens isolated from catheterized patients in Pondicherry, India. Australas Med J 5:344-348

Sundaramoorthy NS, Thothathri S, Bhaskaran M, Kumar A, Prasad G, Nagarajan S (2021) Phages from Ganges River curtail in vitro biofilms and planktonic growth of drug resistant Klebsiella pneumoniae in a zebrafish infection model. AMB Expr 11:27

Tang X, Chen C, Zhu J, Allcock HR, Siedlecki CA, Xu LC (2020) Inhibition of bacterial adhesion and biofilm formation by a textured fluorinated alkoxyphosphazene surface. Bioact Mater 6(2):447-459

Vuotto C, Longo F, Pascolini C, Donelli G, Balice MP, Libori MF, Tiracchia V, Salvia A, Varaldo PE (2017) Biofilm formation and antibiotic resistance in Klebsiella pneumoniae urinary strains. J Appl Microbiol 123(4):1003-1018

Wanjiang, Z., Yao, Z., Changzhen, W., Wenyu, L., Ruichao, L., Fuguang, C., Tian, L., Yanhe, Zh., Stefan, S., Siguo, L. (2019). Characterization of a multidrugresistant porcine Klebsiella pneumoniae sequence type 11 strain coharboring blaKPC-2 and fosA3 on two novel hybrid plasmids. mSphere 4(5): e00590-19.

Wasfi R, Elkhatib WF, Ashour HM (2016) Molecular typing and virulence analysis of multidrug resistant Klebsiella pneumoniae clinical isolates recovered from Egyptian hospitals. Sci Rep 6:38929

Wayne P (2018) Performance standards for antimicrobial susceptibility testing; twenty-fifth informational supplement M100-S25. Clinical and Laboratory Standards Institute, Wayne, p 240

Xu Q, Jiang J, Zhu Z, Xu T, Sheng ZK, Ye M, Xu X, Wang M (2019) Efflux pumps $A c r A B$ and OqxAB contribute to nitrofurantoin resistance in an uropathogenic Klebsiella pneumoniae isolate. Int J Antimicrob Agents 54(2):223-227

Yoon EJ, Oh Y, Jeong SH (2020) Development of tigecycline resistance in carbapenemase-producing Klebsiella pneumoniae sequence type 147 via AcrAB overproduction mediated by replacement of the ramA promoter. Ann Lab Med 40(1):15-20

\section{Publisher's Note}

Springer Nature remains neutral with regard to jurisdictional claims in published maps and institutional affiliations.

\section{Submit your manuscript to a SpringerOpen ${ }^{\circ}$ journal and benefit from:}

- Convenient online submission

- Rigorous peer review

- Open access: articles freely available online

- High visibility within the field

Retaining the copyright to your article

Submit your next manuscript at springeropen.com 